\title{
China in Classics: Narrative Construction of Multiple Texts and the Value of the Times
}

\author{
Ziyong $\mathrm{Wu}^{1}$ \\ ${ }^{1}$ School of Journalism \& Communication, Guangzhou University, Guangzhou, China \\ Correspondence: Ziyong Wu, School of Journalism \& Communication, Guangzhou University, Guangzhou 510006, \\ Guangdong, China.
}

Received: August 10, 2021

Accepted: October 6, $2021 \quad$ Available online: October 8, 2021

doi:10.11114/ijsss.v9i6.5372

URL: https://doi.org/10.11114/ijsss.v9i6.5372

\begin{abstract}
As a spiritual wealth of the Chinese nation, traditional culture is the spiritual power and support for the survival and development of the Chinese people. In the new era, China emphasizes cultural confidence. Its inheritance and promotion of traditional culture have made cultural programs flourish. More recently, specific to multi-dimensional text, learning Chinese culture and extracting spiritual nutrients from TV programs has become an advantageous choice for the broad masses of people to enrich their spiritual life. Through the reconstruction of the text of classics and the narrative construction of the integration of multiple texts, China in Classic Books gives voice to ancient books. By expressing people's humanistic feelings towards classics, it attracts young people's attention and realizes mainstream values with its unique charm. Based on the creation rules and communication effects of China in Classics, this paper analyzes the exploration of the contemporary communication of traditional culture of TV programs.
\end{abstract}

Keywords: China in Classics, narrative construction, multi-dimensional text, reconstruction and reproduction

\section{Introduction}

Metaphorically, classical books are the mirror of traditional Chinese culture. They nourish the spirit of Chinese people. China in Classics (CIC), a series of cultural classics broadcast by China Central Television (CCTV), focuses on well-known ancient Chinese stories and presents the history of Chinese civilization over thousands of years. CIC hits a rating record of the same kind of subject (Shen, 2021), and spreads under the new media platform. Furthermore, it has triggered a wave of "reading classics" in China and attracted the attention of scholars in different fields. At the same time, based on Chinese spirits, this program gains the audience's consistent high praise by showing a high degree of international vision and grasping the intrinsic link and historical context between various regional civilizations to promote "a community with a shared future for mankind" and emphasize core values of people at home and abroad.

In terms of narrative structure, $C I C$ adopts diversified text narrations to replace the single narrative structure of previous variety shows. To paraphrase Fiske John's text is an ideographic structure composed of indispensable symbols and codes in communication activities (John, 2004). Broadcast and television texts can be used as carriers of ideology to control some programs full of potential meanings. They help to focus on those meanings into relatively single and favorable ones, furthering spread them to various social groups, which constitute their audiences. Its form of communication has the effect of mainstream ideology and can serve the interests of the mainstream of society (John, 2005). CIC is interested in China's representative and influential cultural classics through a unique narrative structure, to transform the classics and the quintessence of Chinese civilization. In essence, that cultural value embodies the wisdom and efforts of ancient people into the "text" of the show (Xie \& Luo, 2021). More significantly, CIC endows classics with the characteristics of the times. It enables the traditional cultural text to adapt to the world culture text and constructing the meaning in the interrelated text interaction.

Considering CIC as the research object, this paper first discusses the construction of its multi-text narrative structure from three perspectives of drama text, film text, interview and reality show elements, and gives a simple evaluation of it. Then, it explores the time value and world value highlighted by this program and its multiple texts, and reveals its ability to carry forward traditional culture, dissolve cultural estrangement and advocate "a community with a shared future for mankind". Finally, this paper combs the inspirations of CIC to the production of cultural variety shows from the aspects of audience, art and emotion, and sets up an excellent production paradigm of cultural variety shows. By 
discussing CIC and its "polyphonic" narrative structure, this paper attempts to highlight the unique charm of Chinese culture and express the great mind of Chinese culture to contribute Chinese wisdom to the world.

\section{Construction of a Multi-text Narrative Structure}

CIC has constructed and improved a typical multi-text narrative structure by referring to the narrative and production methods of multiple cultural variety shows. In the era of new media, abundant TV or network programs generated by the increasing cultural needs of audiences promote the pursuit of "good-looking" TV program production (Huang \& Pan, 2018). A narrative structure with multi-text narration as the core is constructed. The narrative structure is a way to combine and arrange various story materials to concrete "a concrete program of narrative expressiveness" (Cheng, 2006). With Chinese Poetry Conference, Everlasting Classics, National Treasure, and other local Chinese programs, which are turning popular in China, the multi-text narrative structure presents a great expressive force for cultural narration. The production team of CIC further improves and innovates this narrative structure by deeply exploring the stories of classic books. It organically combines drama, film and television, interview and other artistic forms and variety shows, tracing the roots of Chinese classics and showing the soul of the Chinese nation. It also fully explores the long-standing, extensive and profound Chinese excellent traditional culture and its functions, realizing transboundary fusion and innovation of "drama + film + interview" and other texts. By discussing the three aspects of drama text, movie text, interview and reality show elements, this part will reveal the function of multi-text narrative structure in enhancing narrative expression and improving narrative efficiency of cultural variety shows. In this way, the boring and lengthy stereotype of cultural variety shows is weakened, and the classics are endowed with new vitality. Better still, it helps to achieve the same frequency resonance of emotion.

\subsection{Drama Text}

CIC reproduces the stories of classics with dramatic texts as the main narrative means. Drama is an ancient art form used for story narration. It is known as mass art from the artistic perspective (Zhang \& Zhang, 2019). CIC reproduces the stories in classics in the form of stage drama, which is equivalent to relying on popular art to make the audience come to the historical scene in person, so that the audience have an opportunity to experience the stories in classics as well as their historical backgrounds. For example, in the fourth episode of the program The Compendium of Materia Medica, the actors' stage performances enable the audience to learn about the hard work of Li Shizhen and generations of his family in revising The Compendium of Materia Medica. Li Shizhen's literal image was transformed into a visual image, allowing the audience to experience the revision process of The Compendium of Materia Medica, showing the dedication of the ancestors for laying the foundation of Chinese medicine. The popularity of drama art makes the audience willing to take the initiative to appreciate classics that are difficult to read so that the story of the classics could be profoundly rooted in the hearts of the people. In the design process of the drama stage of the program, we notice that the program production team adopts a variety of technologies, such as real scene layout, traditional drawing, digital drawing, and 3D animation (Gu, 2020). Clearly, this is in much the same way as China in Stories, another cultural show on CCTV.

The stage design also permeates more stage aesthetics that are commensurate with Chinese tradition. The production team establishes a stage aesthetic that spans time and space, creating an immersive stage that can rotate 270 degrees and a corridor that connects the two Spaces. This stage allows scholars of different times and participants of historical events to enter the "time-space tunnel" and achieve the dialogue between ancient and modern times (Xie \& Luo, 2021). This unique stage design fully embodies the hypothetical features of the drama. It is conducive to the actors showing simple and natural performance emotions. It also helps to achieve the spectacle effect of real dialogue on stage between ancient and modern people. Such exquisite stage layout and performance conception can "break the psychological barrier of the audience, allow room for the audience self-substitution, and achieve the immersive program view and experience" (Xie \& Luo, 2021). With the mutual penetration and high integration of drama text and variety show text, while the drama text serves for the narration of the program. As far as the program is concerned, it provides a new stage for the drama, which belongs to an ancient art form. This gives a new luster to the drama. However, the storytelling method of variety shows based on dramatic texts is not visually enough to vividly reproduce the stories of classic books, especially for audiences outside the scene. Therefore, the film text, as an auxiliary or supplementary function, effectively visualizes the details presented by the drama text and completes the preliminary construction of the multi-text narrative structure.

\subsection{Movie Text}

In CIC, the narrative of the film text mainly serves the visual details of the story and the emotional details of the performance, which complement the narrative of the drama text as the core. The key function of the main stage in CIC is to perform a stage for the actors and restore the larger historical scenes and scenarios. However, two auxiliary stages on both sides of the main stage are mostly designed for actors as the performance stage for small scenes. Clearly, the 
presentation mode is mostly cinematographic and narrates the movie text. As the most unique basis of film language, Montage has a symbiotic relationship with film (Marcel, 1980). The appearance of film text is mainly reflected in the montage, i.e. film editing, of its text narration in the program. In the fourth episode of the program in The Compendium of Materia Medica, the deputy stage was divided into upper and lower levels. On the one hand, with the young Li's desire to be a doctor and on the other hand, the growth of $\mathrm{Li}$ from an ambitious child to an influential doctor. The program edits Li's materials, childhood situation, and his father's dialogue. This connects their dialogue with Li's pictures vividly presented to the audience. The multiplicity of stage time-space is shown in a multi-dimensional way. This highly fits the aesthetic habits of contemporary audiences and makes the audience easier to understand and accept the story. At the same time, in the following scene, multiple images are presented alternately through the combination of different scenes, with close-up shots to reflect the inner world of characters. This vividly expresses Li's grief over the death of his father and the urgent need to shoulder the heavy task of the book revision as well as foregrounding the charm of film language.

In $C I C$, the film text and the drama text intertwine and are simultaneously developed. By selecting significant scenes (i.e. text environment) and events (i.e. drama plot in text) from cinematographic texts, the program reorganizes them on the same big stage by means of juxtaposition and replaces the single spatial-temporal order in the original studio with co-existence (Wang et al., 2020). This requires the stage art (scenery) to transcend the level of the traditional stage drama, take into account the needs of film picture presentation, and attach great importance to detail design. For example, the ancient stone path on the corridor is presented by the LED electronic screen, which enhances the actor's performance belief in the dramatic scene, and also adds details to the multi-dimensional space presented by the high angle shot. Due to the addition of cinematographic shooting, the modern library's art in the fourth episode (of the program) maximizes the pursuit of details. The books on the shelves are one-to-one real books. When Li opens The compendium of Materia Medica, the audience can see its contents through close-up shots. This employment of juxtaposition of the text enriches the functions of the stage of variety shows, presenting the characteristics of the drama stage and the film site. The audience can pay more attention to and understand the subtle actions and expressions of the actors through the audio-visual language of the film and the scene scheduling of the drama when watching the program, so as to make the classic stories achieve the dramatic effect deeply rooted in the hearts of the people. So far, the narrative structure of multiple texts juxtaposed by drama texts and film texts has been preliminarily constructed. However, the interview and reality show elements independent of the story space are in a discourse space, and become storytellers, complements, commentators and reveal behind the story performance, which is another significant text in variety shows in cooperation with the other two texts.

\subsection{Interview \& Reality Show Elements}

As "regular customers" in typical variety shows, the appearance of interviews and reality show elements is an important factor for audiences to identify whether variety shows are entertaining and whe ther they can get emotional resonance. The judges and guests in CIC are separated into two different spaces from the performers on the stage. Chatman (2013) puts forward the term "story space" where the behavior or story takes place and "discourse space" where the storyteller resides. The "story space" refers to the "historical space" where the actors perform in the program. The "discourse space" is relevant to the "interview space" of the compere, experts, and scholars in the observation room. Let us underline that the "historical space" is responsible for the restoration of the historical context of the classic texts. As to the "interview space" it helps to analyze the works through the discourse of experts and scholars, broaden the space outside the narrative text. It also enables the audience to constantly explore and extend the classics in their context to form new perceptions and meanings (Wang et al., 2020). As the actors perform in "historic space", the program occasionally shows the footage of experts and scholars watching performances together with the compere in the "interview space". The guests in "interview space" and the audience in front of the screen watch almost the same images. It is as if they were in the same position from the "god" perspective, which makes the guests in the program experience the same emotional curve as the audience outside the program. After watching the performance, the guests immediately excavate the emotions and historical information of the characters to express their feelings of watching the films. They have an emotional dialogue with the audience, which narrows the emotional distance between the guests and the audience.

Reality shows can present the behaviors of ordinary people in some ordinary states by means of recording. In order to achieve the integrity of the variety show, reduce the preachiness and improve the entertainment, CIC especially adds factual facts to present the authors' status and comperes behind the scenes, making the space behind the actors become the link between reality interviews and historical interpretation (Qin \& Bai, 2020). Meanwhile, the program sets up a reading ceremony, where president of the National Theatre of China, chief screenwriter of CIC, and famous actors who participated in the program to review the classics and read the script. This section presents rehearsals and behind-the-scenes of the program. For example, the actors bantered at the reading ceremony as they usually do in 
private, and the host and actors had fun with each other in rehearsals. These are non-fiction and random contents, which satisfy the audience's curiosity about the behind-the-scenes of the program and make the program full of more real emotional atmospheres. The addition of reality show elements harmonizes the serious artistic style of cultural variety shows, complements with texts such as drama performances, films, and interviews, and constructs the unique format of cultural variety shows from multiple dimensions. When the new type of cultural variety shows represented by CIC appears and wins wide attention and love from the audience, it is bound to reflect the time value and world value of the narrative structure of the fusion of multiple texts, as well as its significance in international culture and art communication.

\section{Time Value and World Value of Multiple Texts}

The success of CIC has provided a great direction for cultural variety shows to pursue the goals of promoting traditional culture, dispelling cultural estrangement and advocating a community of shared future for mankind. This reflects the value of the times and the world shouldered by the multi-text narrative structure. CIC breaks the age, gender, cultural, and even national differences of the audience. It not only arousing their spontaneous review, resonance, and thinking of the classics, but also embodying the common pursuit of human values in the program. Qian (2011) argues for the necessity to enable people to have a deep understanding of the history of the country. In the context of the rapid development of image technology and media, Chinese cultural variety shows adhere to their own cultural values. They are dedicated to broadening the space for creation, seeking national memory, constructing Chinese stories, and shaping the Chinese spirit (Wang, 2020). This is of paramount significance to reproduce China's brilliant historical civilization, inheriting excellent culture and maintaining the national spirits. Besides, the production team measures the program production standards from a highly international perspective, adheres to the combination of "local language" and "international language" (Shen \& Xu, 2019), and relies on the art form popular at home and abroad to make the traditional culture in the world context and expand the audience group of the program. At the same time, it has attracted wide attention from many overseas mainstream media, such as The Wall Street Journal and Radio European Chinese. This narrative structure thoroughly interprets the artistic height of "art without borders" and "art connecting the world". Next, the paper will explore the time value and world value of multi-text, and discuss how CIC becomes a model for the transformation from traditional culture text to variety show text, and eventually to world culture text.

\subsection{Preservation of Traditional Culture \& Promotion of Cultural Confidence}

CIC has demonstrated the ability of cultural variety shows to promote traditional culture and play an important role in enhancing people's cultural confidence. The display of high cultural confidence requires high-quality cultural works based on reality and seeking truth from facts. In essence, common beliefs and feelings can contribute to the cohesion of the society, and it is the traditional culture that is rooted in the heart of the Chinese people. It connects the feelings of the Chinese nation. However, today, when foreign thoughts continue to influence the Chinese people, Chinese society is faced with the crisis of national historical memory loss and cultural inheritance rupture (Qin \& Bai, 2020). It is a long way to go in carrying forward traditional culture and enhance cultural confidence. Cultural confidence originates from the inheritance of the civilization of the Chinese nation. To carry forward the Chinese traditional culture and promote its creative transformation and innovative development, priority is given to telling the Chinese story. CIC, using a multi-text narrative structure, excavates and refines the most quintessential and profound contents of Chinese culture. It presents the world with the extensive and profound traditional culture and the Chinese national spirit of powerful vitality. At the same time, it manifests the responsibility of the production team to tell a good story about China. They realize the deep integration of innovation and inheritance through the new drama concept of cross-space dialogue. With such efforts, the program accurately expresses the value orientation, moral norms and ideological outlook of the Chinese nation. This gives people in modern times a deeper understanding of history and ancestry, and arouses strong cultural confidence in the masses.

The formation of modern culture needs to conform to the times on the basis of preserving the essence of traditional culture. In the new era, people endow ancient books with a new mission to better inherit the excellent traditional culture. Reviewing ancient books and history is a critical way for people to draw wisdom from their ancestors, understand society and understand the country. Minweibangben, which is the core message of the first episode of CIC, The Book of History. This conveys to the audience the idea that the people are fundamental to a peaceful country. This shows that the ideas conveyed by classics are not only oriented to the past, but also related to the present and the future The vigorous vitality of the classic books still has the effect of educating the people today, helping them to accurately interpret the spiritual genealogy of contemporary China. However, the promotion of traditional culture only means that cultural confidence has been initially established. If excellent traditional culture is to be truly carried forward, the cultural barriers between China and foreign countries should be eliminated, so as to make their own culture to the world stage. 


\subsection{Elimination of Cultural Barriers \& Steps onto the World Stage}

The multi-text narrative structure adopted by CIC plays a significant role in dispelling cultural barriers between countries and promoting culture and even a country to the world stage. One of the major prerequisites for a nation to enter the world stage is to eliminate cultural barriers. In the globalized context, the intricate international relations and cultural conflicts have hindered the contact and communication between the cultural circles with significant differences in cultural concepts and representation systems (Chen \& Zhang, 2018). Further, the long-term western "cultural hegemony" and China's cultural connection with the world stage pose a conspicuous challenge. Since 2011, China has been committed to building itself into a culturally powerful nation and stepping up efforts to promote Chinese culture to the world. In this process, it is crucial to make good use of forms and carriers popular with people all over the world and tell Chinese stories through the world discourse system. This is an essential way to spread Chinese culture and arouse the resonance of the world.

The dissemination of visual images among different cultural circles has natural advantages. It can transcend time-space, break through the barriers of all national languages. This is a common language that can be read by all mankind (Shangguan, 2017). CIC adopts a multi-text narrative structure, including art forms such as drama, film and television, which is also a worldwide "language" popular with people all over the world. Through these "languages", the barriers existing between different cultures can be eliminated to a higher degree and the door of intercultural communication can be opened. Chinese stories presented in each episode of the program will be able to strike the hearts of audiences around the world. This can allow audiences around the world to understand Chinese culture and the values advocated by Chinese culture. This kind of global "language" can effectively embody Chinese's desire to produce a culture that shares the core values with the world (Wen \& Ling, 2018), establishes and shows China's international image to the world, master and make good use of the international discourse right, walk into the world and lead the world. From the point of view of the times, classics not only play an indispensable role in increasing cultural diversity and dispelling international cultural estrangement, but also promote the establishment of a community with "a community with a shared future for mankind" through transcending the temporality of their thoughts.

\subsection{Creative Development in Classics \& Anticipation of a Community with a Shared Future}

$\mathrm{CIC}$ has done an excellent job in creatively developing the idea of classics and advocating "a community with a shared future for mankind" by virtue of its profound connotation. To advocate "a community with a shared future for mankind", it is necessary to reinterpret the ideological connotation of ancient classics and creatively develop the element of community in them. Since 2012, China has advocated the concept of "a community with a shared future for mankind", adhering to the consensus and commonality as the basic principle of human destiny community, emphasizing the holistic consciousness, global thinking and human concept (Zhao, 2017). It is a philosophy, which transcends the Western "monism" and the western concept of "subject" ruling "object", and promotes the common development of mankind and the sharing of a bright future (Wen \& Ling, 2018). CIC's third episode tells the story of Sima Qian's statement in Records of the Historian that "the Son of Heaven made the world his home". It conveys the core content of a community with a shared future for humankind. This means there is only one world and that different countries and civilizations can peacefully coexist. In the fifth episode, Analects of Confucius, the program expresses the ancestors' expectations for the realization of a harmonious society through the dramatic artistic techniques of dialogue between modern people and Confucius. They exhort human society to be honest, harmonious. They encourage people to care for each other, unite and help each other. They invite the whole society to share the fruit of labor. These stories embody the principles of "fairness and justice", and the cultural concept of "inclusiveness and diversity". They are in line with the goal of building a world of openness and inclusiveness, lasting peace, universal security, and common prosperity. They also accurately explore the correct concept of justice and interests believed by the Chinese people, presenting to a global audience the values of peace, justice, democracy and freedom that are common to all mankind, advocating peaceful coexistence and common progress of mankind. Not only does this reflect the spirit of the times and responds to the call of the times, but it also endows "a community with a shared future for mankind" with Chinese cultural characteristics The program injects strong impetus into the construction and consolidation of the humanistic foundation, which is the innovative transformation and creative development of Chinese classics in contemporary times. The multi-text narrative structure adopted by CIC not only reflects its value of the times and the world, but also can be correspondingly used as a production paradigm of cultural variety shows to inspire and help the production of other cultural variety shows.

\section{Implications}

Through CIC as a whole and its multi-text narrative structure, the program's foresight in the production of cultural variety shows can be manifested. CIC's accurate prediction of the production of contemporary cultural variety shows and the probability of their success will have a profound impact on the production of similar programs in the future. Below, the implications brought by CIC will be analyzed from three aspects, namely, audience, art and emotion. 


\subsection{Cultural Needs of the Audience \& the Resonance of the National Culture}

CIC is always based on the cultural needs of the audience and arouses national resonance, which is the primary condition for the success of the program. The rapid development of media technology has accelerated the speed of people's acceptance of culture (Zhou \& Zhang, 2020). The transmission mode of traditional cultural programs is rapidly falling out of line with people's cultural needs, which requires continuous innovation and reform in program creation and arouses the resonance of national culture again. $C I C$ has an insight into the cultural needs of the audience and tells the stories in the classics by means of text transformation, reducing the direct output of the content of the classics. The Records of the Historian, Exploitation of the Works of Nature (Tiangong Kaiwu), and other works have been transformed from their dull and difficult images into vivid vernacular performances. Artistic creation should be based on the cultural needs of the public and serve the people with special attention to the depth of the daily life of the masses, and make culture no longer abstract and distant by means of transmission to be acceptable to the public, construct the common cultural memory of the nation. Efforts should be made to create TV programs in both a graceful and popular way, which can leave a strong emotional resonance on the audience. However, to meet the cultural needs of the audience, it is not enough to just do a simple transformation of thinking. Instead, it should be raised to the creation of art and the cultivation of international vision.

\subsection{Various Forms of Artistic Expressions \& the Internationalization of Narrative Paradigm}

The multi-text narrative structure adopted by CIC is a concrete manifestation of enriching artistic expression forms and promoting the internationalization of the narrative paradigm. In cultural variety shows, creators have integrated the timeliness of the book medium, spatial medium of cultural relics, spatial-temporal image medium, and drama performing arts in history and culture (Wang et al., 2020), which greatly enriches the artistic expression forms of variety shows and highlights the aesthetic and ornamental value of the times. At the same time, the use of "world discourse" such as drama and film and television can promote the internationalization of the narrative paradigm of variety shows, which enables traditional culture to be interpreted in the same direction by audiences from all over the world. CIC integrates multiple artistic forms, using the industry's high-level novel audio-visual language and stage industrial technology to create an audio-visual feast such as Dayu Flood Control and other historical scenes. Cultural variety shows need to emphasize that artistic expression forms serve for program narration and explore flexible story expression modes, to give full play to the unique value of culture in promoting exchanges and cooperation between countries. In addition, the rich artistic expression forms, in the final analysis, reflect the core of the story, so that domestic and foreign audiences can gain emotional support.

\subsection{Deep Values of Cultural Stories and the Emotional Expression of the Community}

CIC has made great efforts to explore the core of the story, that is, to tell a good story of "community". Narration is universal. This means human development is inseparable from narration (Deng, 2012). In the complex international environment, storytelling is an effective way to avoid cultural conflicts and pursue the common emotional expression of the world. The production team of CIC, with their reverence and love for Chinese classics, recreated the touching stories in these classics with the help of the uniqueness of the variety stage. They enable the program to transmit universal values applicable to "a community with a shared future of mankind" and create a new path of cultural emotion expression in the context of globalization. Cultural variety shows should deeply explore the characters and stories behind culture so that the stories can be restored to the maximum extent. At the same time, stories need to be told from a new perspective, reflecting the identity and cosmopolitanism of culture in the past, present and future (Wang, 2020). When different sections about historical events and figures are displayed (Gu, 2020), the emotions of all mankind towards human civilization can be expressed.

\section{Conclusion}

With a vast number of classics as the source of Chinese culture, the model that nourishes the soul of the Chinese people inspires people to carry out spiritual reflection. Not only do Classics inscribe the history of the Chinese nation, nurture the present of the Chinese nation, and propel the Chinese nation toward a brilliant future (Ma, 2021), but they also profoundly embody the vision of a beautiful future for mankind, forming a colorful artistic creation that grasps the common ideal value of mankind. In the context of China's emphasis on cultural confidence and the firm goal of a powerful cultural country, CIC exudes solemnity, ritualism, and the power to review history. It actively explores the construction and presentation of the narrative structure of variety shows in parallel with multiple text forms. Adhering to the content-oriented concept, it is endowed with the value of the times, thus shouldering the historical mission and the responsibility of spreading traditional culture. CIC conveys Chinese values from the perspective of art and shows the diversity of world civilizations and the ideal realm of mankind walking cooperatively and sharing civilization with each other (Guo \& Wang, 2020). Under the concept of "a community with a shared future for mankind", China's desire to pursue peace and friendship is deeply reflected with an increasing amount of connection to the world, whether it is 
the Compendium of Materia Medica, contributing to the world medicine, or the Exploitation of the Works of Nature (Tiangong Kaiwu) and Dr. Yuan Nongping's research team that rid the people all over the world of hunger today, or the analects of Confucius Confucianism to the world's future.

\section{Acknowledgements}

The author would like to thank Jialiang Chen for his insightful suggestions and constructive feedback on content relevance, content sufficiency, organization and language quality in an earlier version of this paper.

\section{References}

Chen, B., \& Zhang, L. (2018). Analysis on the Promotion of International Communication Ability Based on Festival Cultural Programs. Television Research, 11, 18-20.

Cheng, S. (2006). The Origin of Influence of TV Programs -- Narration and Structure of TV Programs. University of Journalism, 1, 101-103.

Deng, Z. (2012). Narration, Narrative Paradigm and Narrative Rationality: A Rhetoric Study of Narration. Foreign Language Teaching, 4, 37-41.

Fiske J. (2004). Key Concepts: A Dictionary of Communication and Cultural Studies. Beijing: Xinhua Publishing House.

Fiske, J. (2005). Television culture. Beijing: The Commercial Press.

Gu, S. (2020). China in the Story: Transformation and Breakthrough of Cultural Variety Shows. China Television, 3, 91-95.

Guo, Y., \& Wang, L. (2020). A platform for exchanges and mutual learning between Chinese and foreign cultures and arts -- Comments on Global Variety Show. Contemporary Television, 6, 15-18.

Huang, Z., \& Pan, L. (2018). Making Cultural Programs "Live" -- On the presentation, interpretation and activation of traditional culture in National Treasure. China TV, 4, 52-56.

Ma, Y. (2021). The innovative expression of the Chinese nation's spirit transmission -- based on the thinking of China in Classical Books. Published Wide Angle, 6, 68-70.

Mardan, M., \& He, Z. (1980). Film Language. Beijing: China Film Press.

Qian, M. (2011). Outline of National History. Revision. Beijing: The Commercial Press.

Qin, Q., \& Bai, Y. (2020). Memory, Emotion and Community: Construction of "National Identity" in Cultural TV Programs -- A Case Study of China in Stories. The media, 15, 91-93.

Seymour, C. (2013). The Story and discourse: narrative structure in fiction and film. Beijing: Renmin University of China Press.

Shangguan, X. (2017). The value exploration of image intercultural communication power in publishing "going out". Published Wide Corner, 2, 27-30.

Shen, H. (2021). The Enlightenment from China in Classical Books. Television Research, 2, 4-6.

Shen, Z., \& Xu, J. (2019). Xi Jinping's Practice and Guidance on Chinese Culture in the New Era to the World. Academic Research on Marxist Theory, 6, 72-83.

Wang, X. (2020). How Cultural Variety Shows Tell Chinese Stories -- A Case Study of China within Stories. Contemporary Television, 7, 22-24.

Wang, Y., Xue, Y., \& Xin, X. (2020). Drama-Style Expression: Spatial Turn of Narration in Cultural Variety Shows. China Television, 12, 41-45.

Wen, B., \& Ling. L. (2018). The Community of Human Destiny: Towards the Contemporary Chinese Marxist Cultural Form Leading the World. Journal of suzhou university (philosophy and social science edition), 1, 7-13. https://doi:10.19563/j.cnki.sdzs.2018.01.002.

Xie, Q., \& Luo, M. (2021). The Value Guidance Path of the Cultural Variety Show "China in Classics" from the Perspective of Text. Contemporary Television, 5, 40-44.

Zhang, T., \& Zhang, J. (2019). How China in Stories Realized the "Crossover Breakthrough" of Red Classics Communication. Media, 23, 63-65.

Zhao, K. (2017). The rich connotation and theoretical value of the thought of a community of shared future for mankind. Front, 5, 28-31. 
Zhou, M., \& Zhang, Z. (2020). The Transformation and Enlightenment of the Normal Life of CCTV Cultural Programs. Television Research, 12, 63-66.

\section{Copyrights}

Copyright for this article is retained by the author(s), with first publication rights granted to the journal.

This is an open-access article distributed under the terms and conditions of the Creative Commons Attribution license which permits unrestricted use, distribution, and reproduction in any medium, provided the original work is properly cited. 